\title{
Volunteers' Behavioral Intention in Non-profit Organizations Strategy: A Structural Equation Model
}

$\underline{\text { Authors }}$

Lamberto Zollo, U. of Florence, lamberto.zollo@hotmail.it

Guglielmo Faldetta, Kore U. of Enna, guglielmo.faldetta@unikore.it

Massimiliano Matteo Pellegrini, Princess Sumaya U. for Technology, m.pellegrini@psut.edu.jo Cristiano Ciappei, U. of Florence, cristiano.ciappei@unifi.it 


\title{
Volunteers' Behavioral Intention in Non-profit Organizations Strategy: A Structural Equation Model
}

\begin{abstract}
We drew on organizational behavior theory, psychological functions theory, and socio-anthropological frameworks to propose an integrated model of non-profit organizations (NPOs) strategic management. Structural equation modelling (SEM) was used to evaluate the effect of volunteers' motivations on their behavioral intention to donate. Volunteers' reciprocal behavior was hypothesized as a mediator of such a relationship. Volunteers' motivations were direct predictors of volunteers' intention to donate. Volunteers' reciprocal attitude significantly resulted in a mediating variable of the model. The results help clarify the multidimensional aspects of NPO strategic management, highlighting how NPOs board should strengthen the responsiveness towards volunteers' behavioral signals, which reveal their motivations, attitudes, and intentions. The analyzed latent variables - motivations, reciprocity, and intention to donate - are supposed to represent significant elements in the definition and implementation of an effective strategic process for NPOs. Managerial practical implications for NPOs board are described and discussed.
\end{abstract}

Keywords: Nonprofit Organizations; voluntary sector; strategic management; organizational behavior; reciprocity; structural equation modeling 


\section{Volunteers' Behavioral Intention in Non-profit Organizations Strategy: A Structural Equation Model}

The strategic management of Nonprofit Organizations (NPOs) has become an extensively investigated topic of research in modern managerial literature (Brown \& Iverson, 2004; Kaplan, 2001; Knox \& Gruar, 2007; Tucker, Thorne, \& Gurd, 2013). The delineation of a clear strategic plan for NPOs traditionally challenged nonprofit managers, mainly because this type of logic does not belong to the tradition of such organizations. Clear examples of this situation can be: a problematic assessment of NPOs' performance (Liao, Foreman, \& Sargeant, 2001); NPOs management 'amorphous thinking' (Newman \& Wallender, 1978, p. 26); and a 'delightfully creative chaos' characterizing the voluntary sector (Dahrendorf, 2003, p. XIV). According to Simon (1993, p. 131-132), the management of NPOs implies more criticalities in respect to managing for-profit business, since NPOs surpluses have to be constantly reinvested in the organization in order to maintain a sustainable financial equilibrium in the long term. Similarly, Kaplan (2001, p. 358) stresses managers' difficulties in clearly defining NPO strategy by arguing that effective strategic processes and performance management aimed at the organization's mission are vital for its survival. Stone and colleagues in a series of sequential studies (Stone, 1989; Stone \& Bryson, 2000; Stone \& Crittenden, 1993; Stone, Bigelow, \& Crittenden, 1999) widely investigated strategic management activities in NPOs; they found a quite poor connection among studies on this topic and surely this contributed to the fragmentation of the field. Indeed, the ability to manage the existing tension between NPOs' philanthropic orientation and the strategic orientation imposed by the surrounding environment is crucial for the survival of such organizations.

In the attempt to better consolidate this field, Stone and colleagues (1999) proposed a classification of NPO strategic processes into three broad components, namely formulation, 
content, and implementation. Our main focus of analysis will be on NPOs strategy formulation, which refers to the existing relationships between strategic planning and NPOs' process dynamics, environmental perceptions, and performance (Stone, 1989; Stone et al., 1999). Pertinent literature highlights a frequent absence of a formal strategic planning in NPOs, exception made for environmental and/or political expectations exerted on boards' functions. Specifically, Di Maggio and Powell (1983, p.150) define nonprofits' and charities' adaptation toward required expectations as a form of 'coercive isomorphism', showing how strategic decisions of NPOs managers have been usually implemented as a compulsory response to external pressures, rather than an autonomous and spontaneous solution related to an internal will (Stone et al., 1999). Strategic scholars label such coercive pressures as the ecological, institutional, and adaptation perspectives allowing NPOs' survival (Zajac \& Kraatz, 1993, p.92). Indeed, NPO strategy should conform to the institutional environment, as highlighted by Tucker et al. (2013, p.110) who defines strategy formulation of NPOs as the environmental adaptation in the long term of both mission and objectives. Hence, an inevitable 'societal orientation' emerges in defining and directing NPOs' strategic planning (Liao et al., 2001), and thus highlighting the significant role of social responsibility and a considerable involvement of stakeholders in strategy development (Knox \& Gruar, 2006). This is consistent with Kaplan (2001) who acknowledges the fitting between organizational strategy and the surrounding environment as the essential rationale for NPOs survival. Hence, NPO strategy process entails a thoroughly integration between social demand as a strategic element, stakeholder model of strategic management, and social responsibility toward members, funders, and volunteers, thus defining a 'triangular interplay' between NPOs management, community-based stakeholders, and strategic planning (Jarzabkowski et al., 2007). Brown and Iverson (2004), in applying Miles and Snow's seminal definition of strategy (1978) to NPOs, stress how responsibility toward community, volunteers, and the 
environment influences respectively the three 'problems' of strategy, namely the administrative, the engineering, and the entrepreneurial one. Precisely, the NPOs the administrative problem focuses on delineating the most appropriate NPOs governance structures in order to survive in the surrounding environment and appropriately exploit opportunities and available resources; the entrepreneurial problem refers to the accomplishment of community and stakeholder responsibility; finally, the engineering problem focuses on volunteers' services provision and objectives within the organization. Particularly, it emerges how volunteers play one of the most critical roles in the strategic planning of NPOs, representing the expression of a socially committed community whose needs, satisfactions, and requirements have to be fulfilled. However, scarce attention has been dedicated to the strategic role that volunteers may have in NPOs. The aim of the present research is to analyze how volunteers' intention to donate, motivations, and reciprocal attitude simultaneously function, thus proposing strategic implications to NPOs board management.

Our paper is composed of seven sections including this introduction. In the second section we illustrate the crucial role of volunteers in delineating NPOs strategic process. The third section presents the concept of gift giving and volunteers' intention to donate, which will be hypothesized as the dependent variable of the research. Next, we present the significance of volunteers' psychological motivations, which will be hypothesized as the independent variable of the analysis. In the fifth section we describe the anthropological notion of reciprocity and reciprocal attitude, which will be assumed the mediating variable of the analysis. Then, the empirical analysis is described along with the results. Finally, managerial implications are presented in the discussion section.

\section{Volunteers as a Strategic Resources of NPOs}

Recently, nonprofit literature has recognized volunteers as a unique and critical human resource for NPOs (Karl, Peluchette, \& Hall, 2008). As a consequence of that, 
marketing-oriented strategies aimed at the strengthening of volunteers' recruitment and retention have proliferated (Bussell \& Forbes, 2002; Clary, Snyder, \& Ridge, 1992; Karl et al., 2008; Webb, Green, \& Brashear, 2002). Bussell and Forbes (2002, p.244) point out that NPOs board's understanding of needs, motivations, and behaviors of volunteers is strategic for their effective recruitment and retention. In this context, NPOs' boards strategies interpret volunteers as, firstly, the main customers of NPOs and, at the same time, the main support for NPOs' in providing philanthropic activities (Kaplan, 2001; Karl et al., 2008). Hence, volunteers' retention requires a fit between NPOs strategic formulation and organizational climate, quality of services delivered, and timely assistance (Kaplan, 2001). Houston (2006) intriguingly found that socio-demographic variables of volunteers, such as education or religiosity, are related to their reasons of charitable giving (p.73). Accordingly, Webb et al. (2002) argue that "The ability to measure attitudes toward charitable giving is important for academicians, policymakers, and practitioners alike... such measures aid non-profit practitioners in their efforts to develop effective and efficient marketing strategies to attract and retain donors" (p.300). Latour and Manrai (1989, p.327) accordingly point out how research on the determinants of donation behaviour is significant for testing volunteers' attitude toward both NPOs and volunteering activity.

As a result, volunteers' gift giving attitude and the related intention to donate represent significant elements for NPOs strategic management. It seems plausible to argue that the 'gift exchange model' traditionally developed and applied to the for-profit sector (Akerlof, 1982), may result significant also for NPOs and volunteers who are in this way interpreted as donors. The gift exchange model asserts that since workers' gift giving is ruled by the norm of reciprocity, the organizational board has to implement a gift giving attitude in order to recognize, reward, and incentive individual efforts (Konrad \& Mangel, 2000, p.1227). What emerges is the significant reciprocal exchange that exists between workers and 
management, as well as volunteers and NPO board, a relationship that has important strategic implications. Once NPO management understand volunteers' motivations, attitudes, and behavioral intentions, it is important to enhance the organizational responsiveness toward volunteers' relational signals (Lindenberg, 2000; Lindenberg \& Foss, 2011), to incentive and reward their precious efforts.

Clary and colleagues' stream of research (Clary et al., 1996, 1998; Clary \& Snyder, 1999) represents the widely accepted standard model to investigate donors' motives and attitudes toward volunteering activities. The authors stress how a motivational perspective would result promising in analyzing the main features of volunteerism and theorize a functional approach for assessing volunteers' motivations. Building on this approach, nonprofit scholars have associated volunteers' motivations - such as altruism, social relations, ideology, and personal reward - with NPOs strategic planning process (Wilson, 2000). Donor research scholars found that pro-social motivations - such as altruism and collectivism - are frequently present in donors, along with intrinsic motivations - such as self-esteem and curiosity - and reciprocity (Bednall \& Bove, 2011). Particularly, reciprocal tendency seems appropriate in defining donors' behavioral attitude and intention toward volunteering. Actually, since the NPO context is characterized by interpersonal behavior and social interactions, we interpret volunteers as individuals principally inclined to implement 'positive' behavior according to others' actions, following the psychological notion of 'positive reciprocator' (Perugini, Gallucci, Presaghi, \& Ercolani, 2003, p.255; see also Egloff, Richter, \& Schmukle, 2013).

Finally, it seems widely accepted that three elements such as (a) intention to donate expressed through gift giving - (b) other-oriented and self-oriented motivations, and (c) intention to reciprocate represent determinants of volunteers' behavior, and consequently significant elements for NPOs' strategic planning process. However, to our best knowledge, 
these three components have not been studied in an integrated way in order to propose strategic implications which would result important for NPOs management.

\section{Volunteers' Gift Giving and Intention to Donate}

In this article, gift giving and its logic represent a central issue; in particular, it is important to analyze what are its main mechanisms and motivational aspects. The gift theory is not a new topic for philosophy, anthropology or sociology, where it has been inquired for decades. Economics, particularly behavioral economics, has dealt with the gift as an alternative or complementary explanation to cooperation, altruism, trust and reciprocity (Carmichael \& MacLeod, 1997). In line with this, many authors belonging to the game theory field, experimented the 'gift-exchange game' to explain behaviors in economic contexts (Falk, 2007), particularly in the labor market context (Akerlof, 1982), and recently also in the workplace (Dodlova \& Yudkevich, 2009). In order to understand what is the logic underlying gift giving it is useful to analyze one of the first scholars who studied this topic from an anthropological and sociological perspective, Marcel Mauss (1950). Studying the 'archaic societies', especially the tribes of Polynesia, Melanesia and Northwest America, the author found that gift giving was the main mechanism of circulation of goods, characterized by a system made up of three elements: giving, receiving, and giving back.

Under a Maussian perspective, the circulation of goods starts from the act of giving; this act is somehow able to trigger a cycle by which the other party first receives and then gives back. This kind of circulation of goods does not follow the equivalence rule that is typical of market exchange, i.e. an individual involved in an exchange must give back something economically equivalent to what s/he has received. Unlike this market exchange logic just described, in the gift giving theory there is an uncertainty about when and how the other party will give back; the person who first triggers this cycle by giving something does not know whether, when and how much s/he will receive. Since both givers and reciprocators 
are donors, we cannot consider the giving back act as something that balances such a relationship. Differently from a contractual exchange where, in the end, each party has got her/his due, and each party has given what s/he had to give, in the reciprocal gift giving situation there is no state of equilibrium between the parties. After Mauss, other scholars found that the logic of gift is present also in modern societies (Caillé, 1998). Nowadays, and especially in Western cultures, the gift is often hidden in the relationships with friends and relatives, i.e. those where it is easier to develop interpersonal relationships. We also have the case of the gift towards strangers, for example the gift of blood (Archard, 2002), organs, money to people in need, and the gift in online communities (Faldetta, 2002) or in voluntary organizations (Booth, Park, \& Glomb, 2009).

As we said, the circulation of goods individuated as the gift giving paradigm seems to be based on the norm of reciprocity that drives the actors who have received a benefit from another person to reciprocate by giving back to or helping that person (Gouldner, 1960). Reciprocity is different from economic exchange, where the agents are not free, but obliged by law or third parties to comply with contract obligations; however, it is also different from pure altruism too, which is characterized by isolated and one-directional transfers. According to the logic of gift, what counts in the circulation of goods is not the economical aspect, but the relational one: relationships and ties among people are the priority. In the logic of gift, the focus shifts from what circulates to the meaning of circulation. According to this approach, people's first objective is not seeking some gain; people are not rationally calculating if they are earning something in the exchange, and if the exchanged goods are economically equivalent. What counts is if the circulation of goods is meaningful for the development of relationships (Faldetta, 2011).

Through the logic of gift, we can go beyond the two main paradigms used in social sciences to consider social relationships (Caillé, 1988): (1) methodological individualism, 
according to whom social phenomena can only be explained by showing how they result from the intentional states that motivate the individual actors; (2) holism, which moves from the idea that all the properties of a given system cannot be determined or explained by its parts alone, so the system as a whole determines how the parts behave. What makes these two paradigms similar is a shallow consideration of interpersonal relationships; people - but also organizations, social groups and societies - cannot completely flourish if they are not embedded in the relationships that bind them to the others. Methodological individualism considers people as isolated individuals that are rational and selfish calculators; for this reason, such an approach is unable to consider altruism and relationships apart from selfishness. Holism, on the other hand, considers interpersonal relationships as a matter of fact; individuals have mostly to adhere to those values, rules, culture, and social functions that are required by organizations or society (Gouldner, 1960).

From a motivational point of view, the logic of gift reveals the complexity of human behavior, and its motivational sources. Indeed, gift giving is a multidimensional phenomenon, as it can be analyzed through its economical, social, and personal dimension (Sherry, 1983). Most of the literature on gift giving finds three general and not necessarily mutually exclusive categories of motivations (Wolfinbarger, 1990): self-interest, compliance with social norms, and altruism. A more comprehensive approach on motivations in gift giving comes from Caillé (1998), who finds four motivational sources that can be ideally arranged onto two axes. (1) The first axis is composed by the interest that ranges from two opposite poles: (1.1) interest in something, which is selfish, instrumental, and extrinsic; here the gift is considered as a means of struggle and competition through the creation of consensus and reputation and the acquisition of status and social power; (1.2) interest for someone or disinterest, which is intrinsic and can be linked to altruism and pleasure; in this case the gift cannot be reduced to calculation and instrumentality. (2) The second axis is composed by the degree of freedom 
where we may find as extremes: (2.1) freedom, spontaneity, and gratuitousness, which are related to a free and spontaneous act; (2.2) in contrast to that we have duty, which can come from a social obligation, as in rituals or ceremonies.

According to this approach, the propensity to give cannot be reduced to a single motivation. If we consider utilitarianism and methodological individualism principles, "the sacrifice of instrumental interest would be taken into consideration only if it can pay in terms of the same instrumental interest. You can sacrifice an interest in something only for another interest in something. But of course other three cases are also possible. The material interest may be sacrificed to moral obligation, to disinterest or to spontaneity" (Caillé, 1998, p. 108). If we thought according to holism, we would mainly consider duty and obligation. Through the logic of gift, we can understand the complexity of human behaviour, avoiding the reductionism of methodological individualism and holism. The logic of gift is open and intrinsically relational, because the four motivations support each other in a circular relation: people can continuously pass through all four principles of social action in their lives.

Moreover, we can say that if gift giving is mainly based on interest in something, this can be a sign of selfish behavior, which can bring some advantages to one or both the parties directly involved in the relationship, but can bring disadvantages to some others (Sherry, 1983; Wolfinbarger, 1990). On the contrary, if gift giving is based "on others" as a driving value, it can develop relationships for a wider network of people, such as the community, especially for those behaviors mainly driven by duty and obligation. When gift giving is mainly motivated by interest for someone, gratuitousness and disinterest, relationships that are created can be richer and deeper, because they tend to transcend those people who are directly and indirectly involved in them (Caillé, 1998; Gouldner, 1960).

In the present research, gift giving will be associated with volunteers' intention to donate. In fact, the existing relationships between volunteers' motivations, reciprocal attitude, 
and intention to donate represent the main object of analysis. In the following paragraph we will analyze volunteers' motivations under a functional perspective.

\section{Volunteers' Motivations: The Functional Approach}

Individuals' willingness to help, make personal sacrifices for, and donate to other people in a voluntary way has been extensively studied by researchers of sociology (Cnaan \& Goldberg-Glen, 1991; Wilson, 2000), social psychology (Clary et al., 1992; 1998; Clary \& Snyder, 1999; Omoto \& Snyder, 1995), and management (Bussell \& Forbes, 2002; Latting, 1990). The rationale characterizing donors' attitudes, activities, and more broadly volunteerism refers to, on the one hand, looking for altruistic opportunities to help others; on the other hand, fulfilling personal aims, objectives, and needs (Clary \& Snyder, 1999; Cnaan \& Goldberg-Glen, 1991; Omoto \& Snyder, 1995). This is consistent with Caillé's motivational sources (1998), which we have previously conceptualized in two axes. While the first rationale is linked to 'other-oriented' goals usually guided by altruism - in Caillé's terms freedom, spontaneity, and gratuitousness - the latter involves 'self-oriented' reasons, also called egoistic (Latting, 1990; Stukas, Hoye, Nicholson, Brown, \& Aisbett, 2014) - in Caillé's terms selfish and instrumental interests. The other-oriented motives characterize volunteers' donation behavior highlighting their gratitude and altruism, a behavior recently referred to as 'upstream reciprocity' (Bendall \& Bove, 2011, p.12). On the contrary, the selforiented motives depict volunteers' behavior stressing their expectation to receive something in return, which has been referred to 'downstream reciprocity'. These reciprocity-related motivations represent one of the main reasons why volunteers implement donation behaviour (Deckop, Cirka, \& Andersson, 2013). However, in both altruistic and self-oriented case, volunteers, reciprocators, and donors invest personal skills, money, and time in order to implement, strengthen, or sustain a gift giving relationship, which can be temporarily or longstable, directed to a known person or a stranger (Omoto \& Snyder, 1995; Wilson, 2000). 
Traditionally, in order to understand the reason why individuals volunteer, reciprocate, and donate, literature has used a motivational perspective for assessing the antecedents that lead volunteers to implement such an activity (Clary et al., 1992; 1998). Several propositions have been suggested; from some more simplistic model as a unidimensional one, which considers all motivational antecedents as a single combination of volunteers' reasons named 'rewarding experience' (Cnaan \& Goldberg-Glen, 1991, p.281), to the Latting's bidimensional model (1990), which proposes altruistic and egoistic motivations as the two antecedents of individuals' attitude toward volunteerism. However, the most used model is the functional approach (Clary et al., 1992). It focuses on reasons, purposes, plans and goals of volunteers that underlie and generate social phenomena - in other words, "the personal and social functions being served by an individual's thoughts, feelings, and actions" (Clary et al., 1998, p. 1517; see also Snyder, Clary, \& Stukas, 2000). The authors validated a multidimensional instrument for assessing volunteers' attitudes, namely the Volunteer Functions Inventory (VFI) (Clary et al., 1992; 1998), which progressively represented a standard tool for psychological (Clary \& Snyder, 1999; Snyder et al., 2000) and managerial inquiries (Clary et al., 1996; Gage \& Thapa, 2012; Kinsbergen, Tolsma, \& Ruiter, 2013) on volunteers' motivations.

The VFI consists in a set of six motivational functions that may be classified in (a) relationship-oriented motivations, (b) altruistic other-oriented motives, and (c) egoistic selforiented attitudes. The former motive refers to (a1) volunteers' social attitude, which "reflects motivations concerning relationships with others. Volunteering may offer opportunities to be with one's friends or to engage in an activity viewed favourably by important others" (Clary et al., 1998, p. 1518); such a motivation is thus related to volunteers' willingness to develop and strengthen social interactions (Carlo, Okun, Knight, \& de Guzman, 2005). The otheroriented motivation refers to (b1) volunteers' values, a function that "centers on the 
opportunities that volunteerism provides for individuals to express values related to altruistic and humanitarian concerns for others" (Clary et al., 1998, p. 1517); such a motive has been also referred to as volunteers' 'prosocial value' (Carlo et al., 2005). The remaining four motives express (c1) volunteers' self-oriented attitudes (Clary et al., 1998), namely the understanding function that refers to volunteers' opportunity to learn new experiences and practice knowledge and skills. (c2) The career function, a utilitarian attitude that describes volunteers' willingness to implement the voluntary activities in order to exploit career-related opportunities. (c3) The protective function, which focuses on "protecting the ego from negative features of the self and, in the case of volunteerism, may serve to reduce guilt over being more fortunate than others and to address one's own personal problems" (Clary et al., p. 1518); such a motivation may be interpreted as volunteers' inclination to avoid negative feelings (Carlo et al., 2005). Finally, (c4) the enhancement function that, contrarily to the protective one, focuses on volunteers' positive ego growth and personal development (Clary et al., 1998).

The VFI has been widely considered a valid predictor of volunteers' behavioral intention, for example by Finkelstein (2008) who intriguingly find that while in the short term volunteers' values was the only motivation related to time donation, in the long-term the strongest predictors were understanding and enhancement; Gage and Thapa (2012) find values and understanding to be the strongest motivations for volunteering; similarly, Kinsbergen et al. (2013) find volunteers' understanding to be the only motive positively related to time investment.

In the present research, we build on Okun et al. (1998, p.610) considering the six motivational functions originally identified by Clary and colleagues as "indicators of a more global construct that can be labeled a general motivation to volunteer", and consequently interpret the VFI as a multidimensional second-order factor described as "a more abstract and 
overarching construct reflecting one's overall motivation to volunteer". In support of such a claim, both Clary et al. (1998) and Omoto and Snyder (1995) found positive and significant correlations between the six first-order factors - social, values, understanding, career, protective, enhancement - which reveal a common dependence on a higher order construct that will be named the General Motivation to Volunteer (GMV) (Okun et al., 1998). Hence, the GMV is interpreted as the second-order construct expressing volunteers' overall psychological motivational functions to implement their activity.

According to Clary et al. (1998), the VFI (henceforth GMV) provides relevant managerial implications; indeed, the set of motivations that an organization, both private or public and for-profit or nonprofit, may use it as a strategic tool for attracting, recruiting, and retaining volunteers, and thus paying attention to satisfying their personal psychological functions and purposes (p.1528). Traditionally, managerial research on donation behavior (Latour and Manrai, 1989) relies on the widely accepted belief that individuals' attitudes are antecedents of behavioral intention (Ajzen, 1991; Fishbein \& Ajzen, 1975). Accordingly, Clary et al. (1998) build on psychological research on donation arguing that volunteers' beliefs, values, and attitudes are positively related to donation behavior (p.301). Actually, as well in the present research, the GMV (Clary et al., 1992; 1998; Okun et al., 1998) it is assumed to be an efficient predictor of volunteers' behavioral intention to donate. Hence, building on these observations the following hypothesis is presented:

Hypothesis 1: Volunteers' GMV is positively related to volunteers' behavioral intention to donate.

\section{Volunteers' Reciprocity as a 'Strategic' Mediator in NPOs Management}

In the present section, we present reciprocity as an influential element of volunteers' behavior, and interpret it as a mediating variable of volunteers' motivations and intention to donate. Research in the economic and organizational field has widely demonstrated how the 
norm of reciprocity operates as a general principle in social relationships. The diffusion of the use of reciprocity as an alternative or complementary category to standard economic behaviours is connected to the creation and development, during the last thirty years, of experimental economics and behavioral economics (Bruni, 2008).

According to Kolm (2008), reciprocity is a series of bi-directional transfers independent of one another yet interconnected. Each transfer has to be voluntary, which means there is no external obligation. That is why reciprocity is different from economic exchange, where the agents are not free, but are obliged by law or third parties to comply with contract obligations. Reciprocity is different from pure altruism too, which is characterized by isolated and one-directional transfers. According to the norm of reciprocity (Gouldner, 1960), when people receive a benefit from another person, they feel obligated to reciprocate by giving back to or helping that person. In this sense, reciprocity works as a universal principle, so as if a person receives something s/he can not do anything but give something in turn. Reciprocity can be meant as a kind of social exchange. The distinction between social and economic exchange has been analyzed by Blau (1994), according to whom economic exchange is impersonal in nature and focuses on the quantifiable obligations and extrinsic benefits the parties expect to derive from each discreet contractual transaction. In the social exchange relationship, instead, one person does a favor for another person with only a general, but vague and unenforceable, expectation that the other person will eventually reciprocate in some way. Reciprocity may be distinguished in direct (if two actors give something to one another) and indirect or generalized (when one actor gives something to another and the other gives something to someone else). Direct reciprocity is typically studied in situations of repeated interaction between two individuals. In contrast, indirect or generalized reciprocity can be defined as a beneficial act whose return comes from someone other than the act's recipient (Seinen \& Schram, 2006). In particular, direct reciprocity occurs 
when people act in a more cooperative way as a reply to the kind behavior of others (positive reciprocity) and behave in a hostile manner when treated in an unkind way by others (negative reciprocity). Reciprocal individuals want to be friendly with people that have been previously kind to them, and they want to punish other individuals for unfair or hostile actions.

From a motivational point of view, many studies have demonstrated that the individual attitude and intention to reciprocate is motivated both by 'self-oriented' and 'otheroriented' reasons. Focusing on 'self-oriented' motivations, since the work of Alexander (1987), reciprocity has been strongly related to reputation and status (Engelmann \& Fischbacher, 2009). According to Nowak and Sigmund (1998), individuals act in a strategic and discriminating manner, donating to those who are good and refusing to donate to those who are bad, where individuals are good or bad depending on whether or not they have previously donated. According to this kind of theories, reputation acts as an image scoring, so that prosocial behaviors lead to reputational benefits through reciprocity (Simpson \& Willer, 2008). There are a great number of studies, most of all experiments, which confirm that social status and reputation are good antecedents of the intention to reciprocate. In most experiments, the social status of the potential receiver affects the donor's decision, where the term social status normally refers to an image score, that is a record of the individual's past level of cooperation. In an experiment by Seinen and Schram (2006), donors decide whether or not to provide costly help to the recipients they are matched with, based on information about the recipient's behavior in encounters with third parties. In another experiment, reciprocity is largely based on norms about how often the recipient should have helped others in the past (Bloch, Genicot, \& Ray, 2007). The importance of reputation and social status for reciprocity determines also the existence of group norms, that is a correlation of individual norms within a group. These individual norms are related to the social status that the recipient must have to help him. According to this theory, reciprocity can become a social norm within 
a group; a consequence of the existence of such group norms is that a specific social status may trigger generalized reciprocity in some groups but not in others (Seinen \& Schram, 2006).

Focusing on 'other-oriented' motivations, many studies have demonstrated the positive relation between the individual attitude and intention to reciprocate, and gift-like behaviors as helping and prosocial behaviors (Simpson \& Willer, 2008). Individuals give importance to those who act prosocially towards others, and so they will tend to reciprocate benefactors indirectly (Keysar, Converse, Wang, \& Epley, 2008). This kind of relation is based on the fact that reciprocating a positive behavior encourages and maintains prosocial behavior (Cialdini \& Goldstein, 2004). Some other studies have emphasized the role of giving in fostering reciprocity (Becchetti \& Degli Antoni, 2010), linking this effect to the giver's internal satisfaction with his/her exhibition of giving. The experience of giving benefits may encourage prosocial behavior by increasing the salience and strength of one's identity as a capable and caring contributor (Grant \& Dutton, 2012). More generally, 'other-oriented' motivations should produce more generous and stable reciprocity (Keysar et al., 2008). According to Grant and Dutton (2012), reflecting on receiving may not be sufficient to explain reciprocity. Focusing on receiving a benefit can develop a feeling of gratitude toward the specific individual who is the benefactor, so failing to foster helping behaviour toward other people (Cialdini \& Goldstein, 2004). Moreover, an excessive focus on receiving could cause a feeling of dependency and embarrassing (Fisher, Nadler, \& Whitcher-Alagna, 1982), leading to avoiding opportunities to reciprocate (Flynn \& Brockner, 2003). Hence, people would be more inclined to help others, and so to trigger circuits of reciprocity, when they reflect on giving (Grant \& Dutton, 2012). The positive relation between 'other-oriented' motivations and intention to reciprocate is confirmed also in the case of organizational citizenship behavior (Organ, 1988). These are discretional and voluntary behaviors for which 
individuals are not explicitly rewarded, such as: altruism (helping behaviors directed at specific individuals); generalized compliance (helping behaviors directed at the organizations as a whole); sportsmanship (tolerating the inevitable inconveniences of work without complaining); courtesy (informing others to prevent the occurrence of work-related problems); civic virtue (participating in and being concerned about life of the organization) (Organ, 1988). Organizational citizenship behavior, particularly in the form of helping behaviors, is considered positively related to reciprocity (Deckop et al., 2003).

From what have been said about the motivational complexity of the general motivation to volunteer (GMV), which results particularly coherent to the motivational complexity of the intention to reciprocate, the following hypothesis is presented:

Hypothesis 2a: Volunteers' GMV is positively related to their behavioral intention to reciprocate.

Furthermore, we have noted before that gift giving and reciprocity are strongly related, as the circulation of goods according to the logic of gift is based on the norm of reciprocity. It may seem paradoxical but from this perspective the logic of gift is at the same time free and binding. For Mauss (1950), giving, receiving, and giving back are based on a 'free' acceptance of an 'obligation' to create and maintain social relationships. Giving comes from the awareness of having received something, and on the responsibility of answering this gift (Arnsperger, 2000). In this sense, the individual intention to reciprocate can be a strong enhancement element for the intention to donate, as gift giving is based on the triple obligation of giving, receiving, and giving back (Mauss, 1950). So, building on these observations the following hypothesis is presented:

Hypothesis 2b: Volunteers' intention to reciprocate is positively related to their behavioral intention to donate. 
As a consequence, volunteers' intention to reciprocate is supposed to influence the existing relationship between volunteers' motivations and intention to donate. So, the following hypothesis is presented:

Hypothesis 3: Volunteers' reciprocity significantly mediates the relationship between volunteers' motivation and behavioral intention to donate.

The hypothesized model is illustrated in Figure 1.

Insert Figure 1 about here.

\section{Method}

Sample

The data used in the present research were collected as part of a larger study on NPOs involved in the socio-healthcare services provision. The sampling frame consisted in charitable organizations located in each of the ten provinces of Tuscany Region (Italy) including both lay voluntary associations, named Pubbliche Assistenze ('Public Assistances'), and religious ones named Confraternite della Misericordie ('Confraternities of Mercy'). A ten-page questionnaire including thirty-seven items volunteers was developed in early 2015. Initially, the questionnaire was tested in a Tuscan university student jury made up of ten respondents who were not included in the final sample, in order to check for clarity of vocabulary, facility of completion, and possible ambiguity. After such a pre-test, no substantive change was made to the final questionnaire, which was addressed to NPOs' volunteers and mailed in April 2015 to thirty Tuscan charitable organizations. Data collection yielded 640 questionnaires, and after dropping incomplete surveys a usable sample of 379 questionnaires was utilized in this research, implying a response rate of 59,22\%. As stressed in the cover letter, participation was voluntary, anonymous, and no compensation was provided.

\section{Measures}


Scales used in previous studies were employed to measure the constructs analysed in this research. Volunteers' motivation was measured with the Volunteer Functions Inventory (VFI) developed by Clary et al. (1998), here called GMV. As described in the previous section, the GMV consists in six socio-psychological motivations that describe volunteers' motivation to implement voluntary services, and represents a standard tool in the pertinent literature (Clary et al., 1996; Stukas et al., 2014). Volunteers' motivations were operationalized using the thirty items from the original VIF related to the six dimensions, namely understanding $(\alpha=0,81)$, social $(\alpha=0,83)$, values $(\alpha=0,80)$, protective $(\alpha=0,81)$, career $(\alpha=0,89)$, and enhancement $(\alpha=0,84)$. Volunteers' behavioral intention was measured with a four-item scale originally developed by Coyle and Thorson (2001) and applied to the literature on charitable donation (Ranganathan \& Henley, 2008). Coyle and Thorson obtained a scale reliability estimate of 0,83 . Finally, volunteers' reciprocity was measured with a three-item scale widely used in both economic (Dohmen, Falk, Huffman, \& Sunde, 2009) and psychological research (Perugini et al., 2003) on reciprocal behavior. Although the original 'Personal Norm of Reciprocity' questionnaire (Perugini et al., 2003) consists in three dimensions of reciprocity, namely Beliefs in Reciprocity, Negative Reciprocity, and Positive reciprocity, we employed the Positive Reciprocity scale building on the authors findings of statistically significant distinction between positive reciprocators and negative ones; such a claim has been recently supported by Egloff et al. (2013, p. 786) who find that the items of positive and negative dimensions of reciprocity are independent and unrelated. Perugini et al. (2003) obtained reliability estimates of 0,76. As previously discussed, volunteers are here expected to be positive reciprocators characterized by behavioral intention to donate.

All the items were rated on a five-point Likert-type scale from not at all important (1) to extremely important (5). No item required reverse scoring and values were averaged for 
a possible range of 1 to 5, with higher scores indicating greater volunteers' motivations (GMV), behavioral intention to donate (BI), and positive reciprocity. For each of the main dimensions - the six latent variables of the GMV, BI, and positive reciprocity - a confirmatory factor analysis (CFA) was conducted using SPSS' module AMOS v. 22 (Arbuckle, 2013). AMOS is a CFA and structural equation modelling (SEM) statistical software widely used in social science analysis; SEM is a statistical technique for testing simultaneously a set of regression equations (Hair, Black, Babin, Anderson, \& Tatham, 2006). The maximum likelihood function of AMOS was used to estimate parameters and test the three hypotheses illustrated above (Bagozzi \& Yi, 1988). Firstly, a measurement model was built containing observed variables, also named 'indicators', and unobserved variables, named 'latent' variables, in order to assess goodness-of-fit, validity, reliability, and correlations of the model (Bentler, 1990); second, a structural model was built to assess both the values of standardized item loadings and the hypothesized path coefficients existing between the constructs (Bagozzi \& Yi, 1988; Hu \& Bentler, 1999).

\section{Results}

\section{Sample characteristics}

A summary of the sample characteristics is illustrated in Table 1.

Insert Table 1 about here.

The majority of the respondents were male, and the average age of the sample was approximately 39 years. A majority of the participants were married $(40,4 \%)$ and hold a high school degree (52,2\%), 26,1\% were retired and 16,9\% employed. Approximately one-fourth of the respondents $(25,6 \%)$ have been volunteering for more than fifteen years, and another one-fourth $(25,1 \%)$ between five and ten years.

Means, standard deviations, and scale reliabilities

In Table 2 the scales and item descriptive statistics are shown. 
Insert Table 2 about here.

Mean scores of the GMV items indicated that the respondents' main motivation refer to 'Understanding', with the second item of the variable - 'volunteering lets me learn things through direct, hands on experience' - showing the highest mean $(4,11)$; while the lowest means refers to 'Career' variable, with the fourth item - 'volunteering will help me to succeed in my chosen profession' - showing the smallest mean $(2,19)$. Mean scores of both BI and positive reciprocity scales indicated a respondents' generally positive perception of donation behaviour and reciprocal attitude.

The scales used in the research present good reliability, as shown in Table 2. Specifically, the six dimensions of Clary et al.'s original framework (1998) show Cronbach's $\alpha$ ranging from 0,72 to 0,$89 ; \mathrm{BI}$ indicates good reliability with an $\alpha$ of 0,83 . Finally, the Positive Reciprocity scale indicates sufficient reliability with $\alpha$ of 0,70 .

The results of the correlation analysis of scale items are illustrated in Table 3.

Insert Table 3 about here.

The bivariate correlation analysis showed that the six dimensions of GMV used to measure the volunteers' motivations were significantly and highly correlated between them, showing Pearson $r$ values ranging from 0,394 to $0,736(p<0,01)$. GMV dimensions were significantly and positively related to both the BI dimension, showing $r$ values ranging from 0,287 to 0,504 ( $p<0,01$ ), and Positive Reciprocity, with $r$ values ranging from 0,327 to 0,434 $(p<0,01)$. Moreover, BI was positively associated with Positive Reciprocity $(r=0,440 ; p<$ $0,01)$.

\section{Measurement model}

The goodness-of-fit measures were examined to verify acceptable parsimony of the analyzed model (Bagozzi \& Yi, 1988; Bentler, 1990). Firstly, absolute fit indexes were 
measured. According to Bagozzi and Yi (1988, p.77), "A long standing indicator of the overall goodness-of-fit of any model can be obtained with the $\chi^{2}$-test... a likelihood ratio statistic for testing a hypothesized model against the alternative that the covariance matrix is unconstrained". The Chi-square statistics of the model is significant $\left(\chi^{2}=102,280 p<0,01\right)$ and the relative Chi-square suggests good fit with a T-test of $\chi^{2} / \mathrm{df}=2,223$ (lower than 3 as required) (Bagozzi \& Yi, 1988; Bentler, 1990). The 'Goodness of Fit Index’ (GFI) measures the fit between the hypothesized model and the covariance matrix of the observed variables, indicating model fit for values above 0,95 (Hu and Bentler, 1999). GFI of the model $(0,959)$ suggests acceptable fit. The 'Adjusted Goodness of Fit Index' (AGFI) was also measured, which according to Bagozzi and Yi (1988) should be greater than 0,9. AGFI of the model $(0,919)$ indicates adequate fit.

The last absolute fit index refers to the 'Root Mean Square Error of Approximation' (RMSEA), which measures the fitting of the tested model with the population covariance matrix (Hooper, Coughlan, \& Mullen, 2008, p. 54). RMSEA of the model $(0,057)$ suggests acceptable fit approaching to the value of 0,05 as required (Hu \& Bentler, 1999).

A second category of indexes refers to the relative fit indexes, which examine the discrepancy between the Chi-square values of the hypothesized model and a "baseline" model used as a standard parameter (Bentler, 1990). The most common used are the 'Comparative Fit Index' (CFI), the 'Incremental Fit Index' (IFI) and the 'Normed Fit Index' (NFI) (Bentler, 1990). According to Hu and Bentler (1999), CFI, IFI and NFI above 0,95 are satisfactory. The model indicates good fit indexes $(\mathrm{CFI}=0,974 ; \mathrm{IFI}=0,974 ; \mathrm{NFI}=0,954)$.

The measurement model showed that the path coefficients between the indicators and the latent variable were significant $(p<0,01)$. The results of composite reliability, convergent and discriminant validity of the model are shown in Table 4. 
Insert Table 4 about here.

In order to assess the internal consistency of the indicators, the composite reliability (CR) for each latent construct was estimated (Hair et al., 2006). According to Bagozzi and Yi (1988), CR values higher than 0,6 are required. As Table 3 shows, GMV $(0,882)$, BI $(0,836)$, and positive reciprocity $(0,634)$ show acceptable composite reliability of the model. Convergent validity was assessed by 'Average of Variance Extracted' (AVE), which estimate the indicators' amount of variance accounted by the latent construct (Fornell \& Larcker, 1981; Hair et al., 2006). According to Bagozzi and Yi (1988), AVE values higher than 0,5 indicate good convergent validity. GMV $(0,556)$ and BI $(0,563)$ show acceptable values, while Positive Reciprocity $(0,468)$ is slightly below the limit. Discriminant validity was evaluated by comparing AVE by each constructs to the 'Maximum Shared Variance' (MSV) and the 'Average Shared Variance' (ASV) (Hair et al., 2006). As shown in Table 4, the AVE exceeds both MSV and ASV as requested. Finally, the square values of AVE, reported on the diagonal of the matrix in Table 4, are greater than the inter-construct correlations indicating an adequate reliability of the measurement model (Hair et al., 2006).

The overall fit indexes of the model and the reliability and validity analysis suggest acceptable model fit.

\section{Structural model}

AMOS was then used for estimating the structural model including both individual items loading on the two latent constructs of BI and positive reciprocity, and a first order construct, namely GMV, related to the six dimensions of volunteers' motivations (see Figure 2). As a result, a 'first-order partial aggregation model' was built, which allows to "aggregate across items and components within facets and use the composites so formed for each facet as indicators of one or more global latent variables" (Bagozzi \& Edwards, 1998, p.57). The thirty items of GMV were aggregated into the six dimensions - protective, social, career, 
understanding, enhancement, values - which were treated as indicators of the GMV, considered as a first order latent variable. Bagozzi and Edwards (1998) stress how easiness and the ability to seize the significance of a scale represent the main benefits of such a partial aggregated model.

Insert Figure 2 about here.

Examination of the paths coefficients indicate that GMV significantly influences BI in a direct way $(+0,34 ; p<0,01)$, thus providing statistical support for Hypothesis 1 . The direct effect of GMV on Positive Reciprocity was significant $(+0,56 ; p<0,01)$, thus supporting Hypothesis 2a. Further, the structural model indicates also that the direct relationship between Positive Reciprocity and $\mathrm{BI}$ is significant $(+0,50 ; p<0,01)$, providing statistical support for Hypothesis 2b. Finally, the indirect effect of GMV on BI was also significant $(+0,28 ; p<0,01)$.

In order to test the proposed mediation between GMV, Positive Reciprocity and BI (Hypothesis 3), we follow Kenny, Kashy, and Bolger's (1998) procedure. As the authors suggest, the independent variable (i.e., GMV) is significantly related to the mediator (i.e., Positive Reciprocity), as shown in Table 4 ( $r=0,487 ; p<0,01)$. Second, the independent variable is significantly related to the dependent variable (i.e., $\mathrm{BI})(r=0,516 ; p<0,01)$. Third, the mediator is significantly related to the dependent variable $(r=0,591 ; p<0,01)$. Finally, the relationship between the independent and the dependent variable remains significant and is reduced due to the mediator - the relationship without mediation is significant and equal to 0,62 (0,14 unstandardized) - resulting in partial mediation thus supporting Hypothesis 3 .

In the following section these results will be discussed along with managerial implications.

\section{Discussion and conclusion}


The results of the empirical analysis showed that volunteers' motivations were positively associated with reciprocal attitude and intention to donate. The findings also suggested that positive reciprocity was positively related to volunteers' intention to donate. Hence, all the proposed hypotheses $(H 1, H 2 a, H 2 b, H 3)$ were confirmed by the analysis.

Overall, this study provides plausible support for the notion that a reciprocal attitude of volunteers must be taken in consideration by NPOs managers. These evidences offer interesting considerations for strengthening the strategy of NPOs. Particularly, reciprocity emerged as an important aspect of NPO organizational life and a useful basis for understanding volunteers' intention to donate. In line with research on the role of reciprocity in for-profit organizations (Deckop et al., 2003), we may argue that the reciprocal exchange among volunteers is significant as well as the relationships and exchange between volunteers and NPOs' managers. Following the widely acknowledged importance of a norm of reciprocity in organizational context (Gouldner, 1960), our results indicate that strengthening the reciprocity culture within NPOs can influence the 'triangular interplay' (Jarzabkowski et al., 2007) of such organizations, and consequently their strategic effectiveness. Actually, recent literature on nonprofit management indicates how the main 'problems' of strategy refer to community responsibility, volunteers' as a strategic resource, and governance structure (Brown \& Iverson, 2004). Since volunteers play one of the most important roles within the NPO context, both concerning the provision of socio-health services and the organizational climate, the present research stresses how understanding their motivations, attitudes, and resulting behaviour is crucial for implementing an effective and sustainable strategy (Kaplan, 2001).

Especially concerning the reciprocal tendency existing between volunteers and NPOs' managers - the previously defined 'entrepreneurial problem' of strategy (Brown \& Iverson, 2004; Miles \& Snow, 1978) - the present study provides interesting insights to the 
modern debate on 'relational signaling' (Lindenberg, 2000; Lindenberg \& Foss, 2011), a scarcely investigated topic in the nonprofit context. According to Lindenberg (2000, p.15), "people are able to commit themselves to a cooperative disposition and are able to effectively signal this commitment". More recently, Lindenberg and Foss (2011, p.515) conclude that "relational signals allow management and employees to communicate their commitment to common goals and to each of the individuals who contribute to them". Monitoring such relational signals in NPOs improves both the volunteers' behavior trustworthiness and the stability of the overall organizational functioning. Applying the relational signaling model to the nonprofit context, it actually emerges how volunteers' motivations, reciprocal behavior, and intention to donate influence the stability of the other volunteers along with the NPO management. Hence, the ability of receiving volunteers' positive relational signals resulting from their behavior is important for the NPO strategy.

Once approved the role played by volunteers' motivations, reciprocity, and intention to donate within the nonprofit context, managers can use such elements as strategic levers for improving the NPO's effectiveness. Volunteers' behavioral intention to donate occurs within an organizational context characterized by a reciprocal attitude between the NPO and its resources. Thanks to values, identity, and culture that allow the NPO to create an effective territorial embeddedness, it is possible to strengthen the reciprocal attitude which is interpreted as a strategic element of NPOs board. Specifically, one of the most critical element refers to the relation between volunteers' commitment and the resulting organization's responsiveness. While the former refers to volunteers' gift-giving and intention to donate - their time, money, know-how - to the organization, the latter refers to NPO management ability to seize such relational 'signals' and consequently implement appropriate strategies. NPO's responsiveness should aim to focus the strategic decision processes on the 'mediator' of volunteers' motivations and intention to donate, which is their reciprocal 
attitude. By applying Akerlof's model of gift exchange (1982) to the nonprofit context, we argue that NPOs should respond to volunteers' relational signals in a reciprocal way, for example by paying attention to volunteers' motivations and thus being able to appropriately rewarding their efforts.

Overall, NPO's managers should pay attention to the quality of relationship with volunteers. Again, the kind of reciprocity that characterizes this relationship is crucial (UhlBien \& Maslyin, 2003). According to Sparrowe and Liden (1997), the quality of relationship depends on the fact that a balanced or generalized reciprocity is used. Balanced reciprocity is characterized by fixed timing and exchange of benefits of equal value; if the volunteers should follow a norm of balanced reciprocity, they would tend to calculate what they have received from the NPO's managers giving back something economically equivalent. They would be prevalently motivated by self-oriented motivations, and they would show lower commitment towards the organization. Generalized reciprocity is characterized by less concern for the equivalence and timing of returns, and a focus on generosity; if the volunteers should follow a norm of generalized reciprocity, they would tend to spontaneously and voluntarily donate. They would be prevalently motivated by other-oriented motivations, and they would show a higher commitment towards the organization and a deep concern for the others.

The present study has numerous limitations that should be noted. Firstly, the use of subjective self-reports questionnaires may have influenced the measurement accuracy of the analyzed variables. The sampling of Tuscan volunteers limits the generalizability of the findings to broader Italian geographical regions. Moreover, volunteers' gender, age, education, and employment may have influenced the relationships of the proposed model. Future studies should address such limitations by expanding the model in different geographical areas and contexts, for example the business one. Actually, it would be 
interesting to apply the analyzed variables to the traditional workplace context, in order to suggest significant differences between NPOs' and for-profit companies' implications.

Workers' motivations, reciprocal attitude, and intention to donate may result significant in enhancing the strategic management of commercial realities as well as of NPOs. Particularly, implications regarding relationship signaling theory and organizational citizenship behavior would benefit from the proposed model also in for-profit contexts. 


\section{REFERENCES}

Ajzen, I. 1991. The theory of planned behavior. Organizational Behavior and Human Decision Processes, 50(2): 179-211.

Akerlof, G. A. 1982. Labor Contracts as a Partial Gift Exchange. Quarterly Journal of Economics, 97(4): 543-569.

Alexander, R. D. 1987. The Biology of Moral Systems. New York: Aldine de Gruyter.

Arbuckle, J. L. 2013. IBM SPSS Amos 22 user's guide. Crawfordville: Amos Development Corporation.

Archard, D. 2002. Selling yourself: Titmuss's argument against a market in blood. The Journal of Ethics, 6(1): 87-102.

Arnsperger, C. 2000. Methodological altruism as an alternative foundation for individual optimization. Ethical Theory and Moral Practice, 3: 115-136.

Bagozzi, R. P., \& Edwards, J. R. 1998. A general approach for representing constructs in organizational research. Organizational Research Methods, 1(1): 45-87.

Bagozzi, R. P., \& Yi, Y. 1988. On the evaluation of structural equation models. Journal of the Academy of Marketing Science, 16(1): 74-94.

Becchetti, L., \& Degli Antoni, G. 2010. The sources of happiness: Evidence from the investment game. Journal of Economic Psychology, 31: 498-509.

Bednall, T. C., \& Bove, L. L. 2011. Donating blood: a meta-analytic review of self-reported motivators and deterrents. Transfusion Medicine Reviews, 25(4): 317-334.

Bennett, R., \& Sargeant, A. 2005. The non-profit marketing landscape: guest editors' introduction to a special section. Journal of Business Research, 58(6): 797-805.

Bentler, P. M. 1990. Comparative fit indexes in structural models. Psychological Bulletin, 107(2): 238-246.

Blau, P. 1994. Structural Contexts of Opportunities. Chicago: University of Chicago Press.

Bloch, F., Genicot, G., \& Ray, D. 2007. Reciprocity in Groups and the Limits to Social Capital. American Economic Review, 97: 65-69.

Booth, J. E., Park, K. W., \& Glomb, T. M. 2009. Employer-supported volunteering benefits: gift exchange among employers, employees, and volunteer organizations. Human Resource Management, 48(2): 227-249.

Brown, W. A., \& Iverson, J. O. 2004. Exploring strategy and board structure in non-profit organizations. Non-profit and Voluntary Sector Quarterly, 33(3): 377-400.

Bruni, L. 2008. Reciprocity, altruism and civil society. London: Routledge.

Bussell, H., \& Forbes, D. 2002. Understanding the volunteer market: The what, where, who and why of volunteering. International Journal of Non-profit and Voluntary Sector Marketing, 7(3): 244-257.

Caillé, A. 1998. Le tiers paradigme. Anthropologie philosophique du don. Paris: Editions La Découverte.

Carlo, G., Okun, M. A., Knight, G. P., \& de Guzman, M. R. T. 2005. The interplay of traits and motives on volunteering: Agreeableness, extraversion and prosocial value motivation. Personality and Individual Differences, 38(6): 1293-1305. 
Carmichael, H. L., \& MacLeod, W. B. 1997. Gift giving and the evolution of cooperation. International Economic Review, 38(3): 485-509.

Cialdini, R. B., \& Goldstein, N. J. 2004. Social influence: Compliance and conformity. Annual Review of Psychology, 55: 591-621.

Clary, E. G., \& Snyder, M. 1999. The motivations to volunteer theoretical and practical considerations. Current Directions in Psychological Science, 8(5): 156-159.

Clary, E. G., Snyder, M., \& Ridge, R. 1992. Volunteers' motivations: A functional strategy for the recruitment, placement, and retention of volunteers. Non-profit Management and Leadership, 2(4): 333-350.

Clary, E. G., Snyder, M., \& Stukas, A. A. 1996. Volunteers' motivations: Findings from a national survey. Non-profit and Voluntary Sector Quarterly, 25(4): 485-505.

Clary, E. G., Snyder, M., Ridge, R. D., Copeland, J., Stukas, A. A., Haugen, J., \& Miene, P. 1998. Understanding and assessing the motivations of volunteers: a functional approach. Journal of Personality and Social Psychology, 74(6): 1516-1530.

Cnaan, R. A., \& Goldberg-Glen, R. S. 1991. Measuring motivation to volunteer in human services. Journal of Applied Behavioral Science, 27(3): 269-284.

Dahrendorf, R. 2003. Foreword. In J. Kendall (ed.), The Voluntary Sector: comparative perspectives in the UK. London: Routledge.

Deckop, J. R., Cirka, C. C., \& Andersson, L. M. 2003. Doing unto others: The reciprocity of helping behavior in organizations. Journal of Business Ethics, 47(2): 101-113.

DiMaggio, P. J., \& Powell, W. W. 1983. The iron cage revisited: Institutional isomorphism and collective rationality in organizational fields. American Sociological Review, 48(2): 147-160.

Dodlova, M., \& Yudkevich, M. 2009. Gift exchange in the workplace. Human Resource Management Review, 19(1): 23-38.

Egloff, B., Richter, D., \& Schmukle, S. C. 2013. Need for conclusive evidence that positive and negative reciprocity are unrelated. Proceedings of the National Academy of Sciences, 110(9): E786-E786.

Engelmann, D., \& Fischbacher, U. 2009. Indirect reciprocity and strategic reputation building in an experiment helping game. Games and Economic Behavior, 67(2): 399-407.

Faldetta, G. 2002. The content of freedom in resources: The open source model. Journal of Business Ethics, 39(1-2): 179-188.

Faldetta, G. 2011. The Logic of Gift and Gratuitousness in Business Relationships. Journal of Business Ethics, 100: 67-77.

Falk, A. 2007. Gift Exchange in the Field. Econometrica, 75(5): 1501-1511.

Finkelstein, M. A. 2008. Predictors of volunteer time: The changing contributions of motive fulfillment and role identity. Social Behavior and Personality, 36(10): 1353-1363.

Fishbein, M., \& Ajzen, I. 1975. Belief, attitude, intention and behavior: An introduction to theory and research. Reading: Addison-Wesley Publishing Company.

Fisher, J. D., Nadler, A., \& Whitcher-Alagna, S. 1982. Recipient reactions to aid. Psychological Bulletin, 91: 27-54. 
Flynn, F. J., \& Brockner, J. 2003. It's different to give than to receive: Predictors of givers' and receivers' reactions to favor exchange. Journal of Applied Psychology, 88: 10341045.

Gage, R. L., \& Thapa, B. 2012. Volunteer motivations and constraints among college students analysis of the volunteer function inventory and leisure constraints models. Nonprofit and Voluntary Sector Quarterly, 41(3): 405-430.

Gouldner, A. 1960. The Norm of Reciprocity: A Preliminary Statement. American Sociological Review, 25(2): 161-178.

Grant, A., \& Dutton, J. 2012. Beneficiary or Benefactor: Are People More Prosocial When They Reflect on Receiving or Giving?. Psychological Science, 23: 1033-1039.

Hair, J. F., Black, W. C., Babin, B. J., Anderson, R. E., \& Tatham, R. L. 2006. Multivariate data analysis (Vol. 6). New York: Pearson Prentice Hall.

Hooper, D., Coughlan, J., Mullen, M. 2008. Structural Equation Modelling: Guidelines for Determining Model Fit. Electronic Journal of Business Research Methods, 6(1): 5360.

Houston, D. J. 2006. "Walking the walk" of public service motivation: Public employees and charitable gifts of time, blood, and money. Journal of Public Administration Research and Theory, 16(1): 67-86.

Hu, L. T., \& Bentler, P. M. (1999). Cutoff criteria for fit indexes in covariance structure analysis: Conventional criteria versus new alternatives. Structural Equation Modeling: a Multidisciplinary Journal, 6(1): 1-55.

Jarzabkowski, P., Balogun, J., \& Seidl, D. 2007. Strategizing: The challenges of a practice perspective. Human Relations, 60(1): 5-27.

Kaplan, R. S. 2001. Strategic performance measurement and management in non-profit organizations. Non-profit Management and Leadership, 11(3): 353-370.

Karl, K. A., Peluchette, J. V., \& Hall, L. M. 2008. Give them something to smile about: A marketing strategy for recruiting and retaining volunteers. Journal of Non-profit \& Public Sector Marketing, 20(1): 71-96.

Kenny, D. A., Kashy, D. A., \& Bolger, N. 1998. Data analysis in social psychology. In D. T. Gilbert, S. T. Fiske, \& G. Lindzey (Eds.), The handbook of social psychology (4th ed.: 233-65). Boston: McGraw-Hill.

Keysar, B., Converse, B. A., Wang, J., \& Epley, N. 2008. Reciprocity Is Not Give and Take. Asymmetric Reciprocity to Positive and Negative Acts. Psychological Science, 19(2): 1280-1286.

Kinsbergen, S., Tolsma, J., \& Ruiter, S. 2013. Bringing the beneficiary closer: Explanations for volunteering time in Dutch Private Development Initiatives. Non-profit and Voluntary Sector Quarterly, 42(1): 59-83.

Knox, S., \& Gruar, C. 2007. The application of stakeholder theory to relationship marketing strategy development in a non-profit organization. Journal of Business Ethics, 75(2): 115-135.

Kolm, S. 2008. Reciprocity: An Economics of Social Relations. Cambridge: Cambridge University Press. 
LaTour, S. A., \& Manrai, A. K. 1989. Interactive impact of informational and normative influence on donations. Journal of Marketing Research, 26(3): 327-335.

Latting, J. K. 1990. Motivational differences between Black and White volunteers. Non-profit and Voluntary Sector Quarterly, 19(2): 121-135.

Liao, M. N., Foreman, S., \& Sargeant, A. 2001. Market versus societal orientation in the nonprofit context. International Journal of Non-profit and Voluntary Sector Marketing, 6(3): 254-268.

Lindenberg, S. 2000. It takes both trust and lack of mistrust: The workings of cooperation and relational signaling in contractual relationships. Journal of Management and Governance, 4(1): 11-33.

Lindenberg, S., \& Foss, N. J. 2011. Managing joint production motivation: The role of goal framing and governance mechanisms. Academy of Management Review, 36(3): 500525.

Mauss, M. 1950. Sociologie et anthropologie. Paris: Presses Universitaires de France.

Newman, W. H., \& Wallender, H. W. 1978. Managing Not-for-Prof it Enterprises. Academy of Management Review, 3(1): 24-31.

Nowak, M. A., \& Sigmund, K. 1998. The Dynamics of Indirect Reciprocity. Journal of Theoretical Biology, 194: 561-574.

Okun, M. A., Barr, A., \& Herzog, A. 1998. Motivation to volunteer by older adults: a test of competing measurement models. Psychology and Aging, 13(4): 608-621.

Omoto, A. M., \& Snyder, M. 1995. Sustained helping without obligation: motivation, longevity of service, and perceived attitude change among AIDS volunteers. Journal of Personality and Social Psychology, 68(4): 671-686.

Organ, D. W. 1988. Organizational Citizenship behavior: The good soldier syndrome. Lexington: Lexington Books.

Peloza, J., \& Hassay, D. N. 2006. Intra-organizational volunteerism: Good soldiers, good deeds and good politics. Journal of Business Ethics, 64(4): 357-379.

Perugini, M., Gallucci, M., Presaghi, F., \& Ercolani, A. P. 2003. The personal norm of reciprocity. European Journal of Personality, 17(4): 251-283.

Ranganathan, S. K., \& Henley, W. H. 2008. Determinants of charitable donation intentions: a structural equation model. International Journal of Non-profit and Voluntary Sector Marketing, 13(1): 1-11.

Sargeant, A., \& Woodliffe, L. 2007. Gift giving: an interdisciplinary review. International Journal of Non-profit and Voluntary Sector Marketing, 12(4): 275-307.

Seinen, I., \& Schram, A. 2006. Social status and group norms: Indirect reciprocity in a repeated helping experiment. European Economic Review, 50: 581-602.

Sherry, J. F. Jr. 1983. Gift-giving in anthropological perspective. Journal of Consumer Research, 10(2): 157-168.

Simon, H. A. 1993. Strategy and organizational evolution. Strategic Management Journal, 14(S2): 131-142.

Simpson, B., \& Willer, R. 2008. Altruism and indirect reciprocity: The interaction of person and situation in prosocial behavior. Social Psychology Quarterly, 71(1): 37-52. 
Snyder M, Clary EG, Stukas AA. 2000. The functional approach to volunteerism. In Why We Evaluate: Functions of Attitudes, (ed.) GR Maio, JM Olson, pp. 365-93. Erlbaum, Mahwah.

Sparrowe, R. T., \& Liden, R. C. 1997. Process and structure in leader-member exchange. Academy of Management Review, 22: 522-552.

Stone, M. M. 1989. Planning as strategy in non-profit organizations: An exploratory study. Non-profit and Voluntary Sector Quarterly, 18(4): 297-315.

Stone, M. M., \& Bryson, J. M. 2000. Strategic management in the non-profit sector. In J. Rabin, G. J. Miller, \& W. B. Hildreth (Eds.), Handbook of strategic management (pp. 749-762). New York: Marcel Dekker.

Stone, M. M., \& Crittenden, W. 1993. A guide to journal articles on strategic management in non-profit organizations, 1977 to 1992. Non-profit Management and Leadership, 4(2): 193-213.

Stone, M. M., Bigelow, B., \& Crittenden, W. 1999. Research on strategic management in non-profit organizations synthesis, analysis, and future directions. Administration \& Society, 31(3): 378-423.

Stukas, A. A., Hoye, R., Nicholson, M., Brown, K. M., \& Aisbett, L. 2014. Motivations to Volunteer and Their Associations With Volunteers' Well-Being. Non-profit and Voluntary Sector Quarterly, 43: 1-21.

Tucker, B. P., Thorne, H., \& Gurd, B. W. 2013. Uncharted Waters: Exploring the Relationship between Strategy Processes and Management Control Systems in the Non-profit Sector. Non-profit Management and Leadership, 24(1): 109-133.

Uhl-Bien, M., \& Maslyn, J.M. 2003. Reciprocity in manager-subordinate relationships: Components, configurations, and outcomes. Journal of Management, 29(4): 511-532.

Webb, D. J., Green, C. L., \& Brashear, T. G. 2000. Development and validation of scales to measure attitudes influencing monetary donations to charitable organizations. Journal of the Academy of Marketing Science, 28(2): 299-309.

Wilson, J. 2000. Volunteering. Annual Review of Sociology, 26: 215-240.

Wolfinbarger, M. F. 1990. Motivations and Symbolism in Gift-Giving Behavior. Advances in Consumer Research, 17: 699-706.

Zajac, E. J., \& Kraatz, M. S. 1993. A diametric forces model of strategic change: Assessing the antecedents and consequences of restructuring in the higher education industry. Strategic Management Journal, 14(S1): 83-102. 


\section{TABLE 1. Sample Characteristic}

$\begin{array}{lrr}\text { Variable } & \text { Frequency } & \text { Valid Perce } \\ \text { Gender } & & \\ \text { Male } & 248 & 65,4 \\ \text { Female } & 131 & 34,6 \\ & & \\ \text { Age } & & \\ 18-24 & 80 & 21,1 \\ 25-29 & 40 & 10,6 \\ 30-35 & 32 & 8,4 \\ 36-40 & 29 & 7,7 \\ 41-50 & 51 & 13,5 \\ 51-60 & 46 & 12,2 \\ \text { Over } 60 & 101 & 26,6\end{array}$

\section{Status}

Single

In a relationship

Married

Widowed

Separated, divorced

Other

\section{Education level}

Primary school

Secondary school

High school

Bachelor's degree

Master's degree

$\mathrm{PhD}$

\section{Employment}

Student

14,8

Employee
40,4

15

4,0

18

4,7
56

14

83

198

30

33

15

64 


$\begin{array}{lrr}\text { Worker } & 38 & 10,0 \\ \text { Merchant } & 7 & 1,8 \\ \text { Freelance } & 33 & 8,7 \\ \text { Teacher } & 5 & 1,3 \\ \text { Artisan } & 9 & 2,4 \\ \text { Housewife } & 4 & 1,1 \\ \text { Retired } & 99 & 26,1 \\ \text { Unemployed } & 38 & 10,0 \\ \text { Other } & 26 & 6,9 \\ & & \\ \text { Years of Volunteering } & & \\ \text { Less than 1 } & 34 & 9,0 \\ \text { 1-4 } & 103 & 27,2 \\ \text { 5-10 } & 95 & 25,1 \\ \text { 10-15 } & 50 & 13,2 \\ \text { More than 15 } & 97 & 25,6\end{array}$

TABLE 2. Scales and item descriptive statistics

Scale

Mean

SD

$\alpha$

Item

\section{Volunteer Function Inventory (GMV)}

A) Protective

1. No matter how bad I've been feeling,

volunteering helps me to forget about it.

2. By volunteering I feel less lonely.

3. Doing volunteer work relieves me of some

of the guilt over being more fortunate than others.

4. Volunteering helps me work through by own personal problems.

5. Volunteering is a good escape from my own troubles. 
1. My friends volunteer. 3,15

2. People I'm close to want me to volunteer.

3. People I know share an interest in community service.

4. Others with whom I am close place a high value on community service.

5. Volunteering is an important activity to the people I know best.

C) Career

1. Volunteering can help me to get my foot in the door at a place where I would like to work.

2. I can make new contacts that might help my business or career.

3. Volunteering allows me to explore different career options.

4. Volunteering will help me to succeed in my chosen profession.

5. Volunteering experience will look good on my resumé.

\section{D) Understanding}

1. I can learn more about the cause for which I am working

2. Volunteering allows me to gain a new perspective on things.

3. Volunteering lets me learn things through direct, 4,11 hands on experience.

4. I can learn how to deal with a variety of people.

5. I can explore my own strengths.

1. Volunteering makes me feel important.

2. Volunteering increases my self-esteem.

3. Volunteering makes me feel needed. 
4. Volunteering makes me feel better about

myself.

5. Volunteering is a way to make new friends.

F) Values

1. I am concerned about those less fortunate than myself.

2. I am genuinely concerned about the particular group I am serving.

3. I feel compassion toward people in need.

4. I feel it is important to help others.

5. I can do something for a cause that is important to me.

Behavioral Intention to Donate

1. It is very likely that I will donate.

2. I will donate next time.

3. I will definitely donate.

4. I would recommend to donate.

\section{Positive Reciprocity}

0,70

1. If someone does me a favor, I am prepared to return it.

2. I go out of my way to help somebody who has been kind to me before.

3. I am ready to undergo personal costs to help somebody who has helped me before. 
TABLE 3. Correlation matrix of latent dimensions

\begin{tabular}{|l|rrrrrrrr|}
\hline & 1 & 2 & 3 & 4 & 5 & 6 & 7 & 8 \\
\hline Protective & 1,000 & & & & & & & \\
Social &, $576^{*}$ & 1,000 & & & & & & \\
Career &, $577^{*}$ &, $473^{*}$ & 1,000 & & & & & \\
Understanding &, $538^{*}$ &, $497^{*}$ &, $559^{*}$ & 1,000 & & & & \\
Enhancement &, $736^{*}$ &, $560^{*}$ &, $559^{*}$ &, $638^{*}$ & 1,000 & & & \\
Values &, $581^{*}$ &, $552^{*}$ &, $394^{*}$ &, $584^{*}$ &, $592^{*}$ & 1,000 & & \\
Reciprocity &, $409^{*}$ &, $327^{*}$ &, $428^{*}$ &, $347^{*}$ &, $397^{*}$ &, $434^{*}$ & 1,000 & \\
BI &, $441^{*}$ &, $384^{*}$ &, $376^{*}$ &, $287^{*}$ &, $301^{*}$ &, $504^{*}$ &, $440^{*}$ & 1,000 \\
\hline
\end{tabular}

$* p<.01$

TABLE 4. Composite reliability, constructs variances, and interconstructs correlations.

\begin{tabular}{|l|c|c|c|c|c|c|c|}
\hline & CR & AVE & MSV & ASV & Reciprocity & GMV & BI \\
\hline Reciprocity & 0,634 & 0,468 & 0,349 & 0,293 & $0,684^{a}$ & & \\
\hline GMV & 0,882 & 0,556 & 0,266 & 0,252 & $0,487^{*}$ & $0,746^{a}$ & \\
\hline BI & 0,836 & 0,563 & 0,349 & 0,308 & $0,591^{*}$ & $0,516^{*}$ & $0,750^{a}$ \\
\hline
\end{tabular}

${ }^{\mathrm{a}}$ The square value of AVE is reported along the diagonal

$* p<.01$

CR: Composite reliability

AVE: Average variance extracted

MSV: Maximum shared variance

ASV: Average shared variance 
FIGURE 1. Summary of hypothesized relationships.

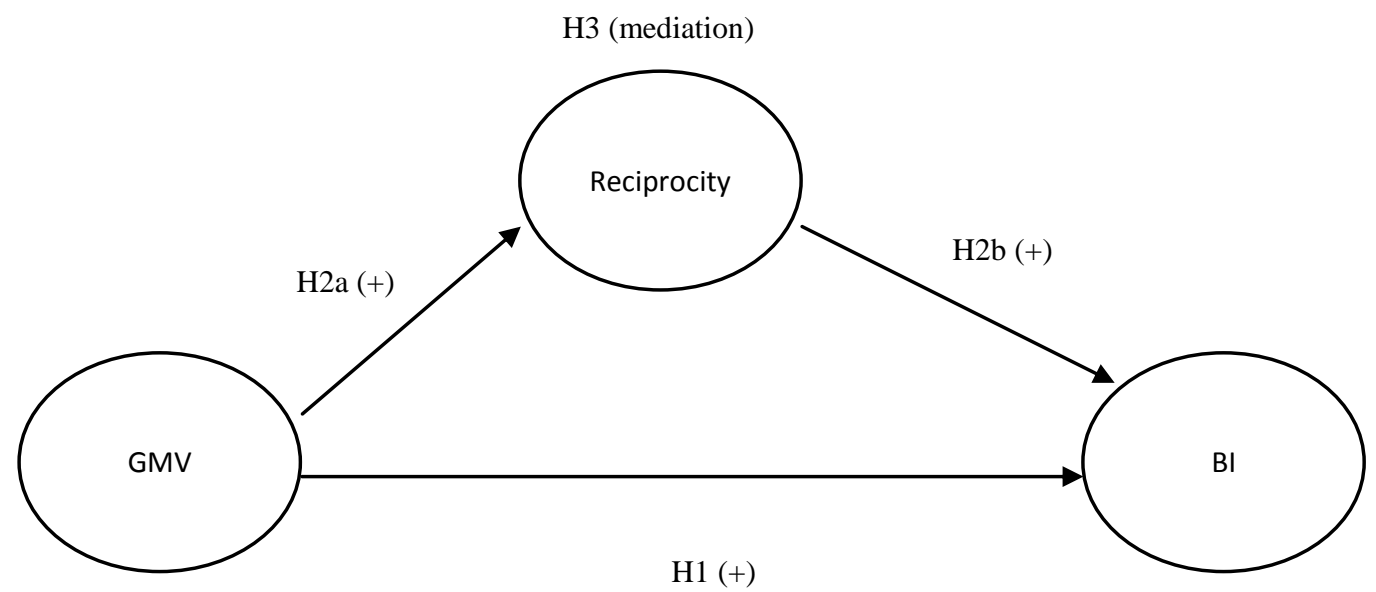

GMV = General Motivation to Volunteer

$\mathrm{BI}=$ Behavioral Intention to Donate

Reciprocity = Positive Reciprocal Attitude

FIGURE 2. Summary of measurement and structural relationships.

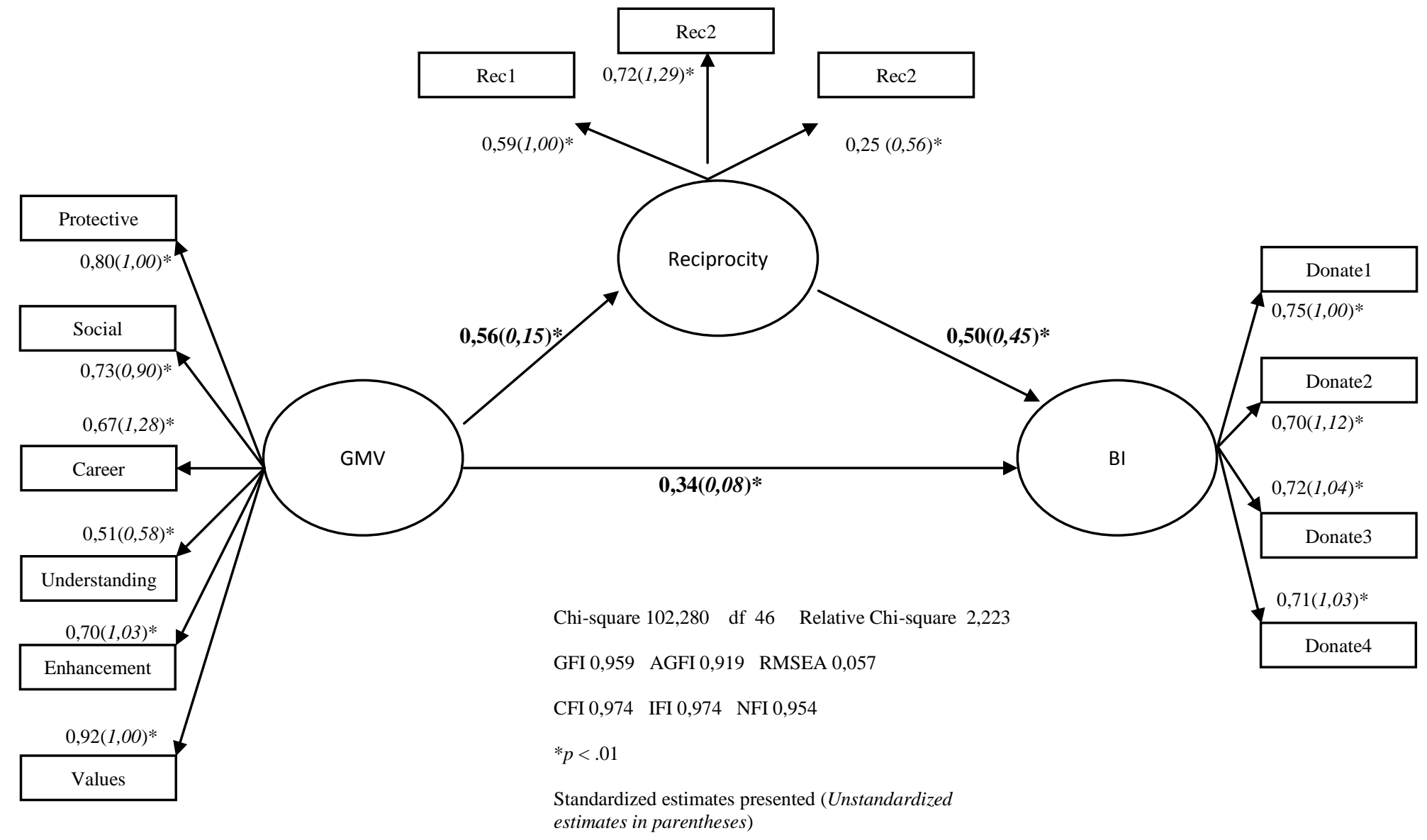

